\title{
A Rare Cause of Carbon Monoxide Intoxication: Hookah
}

\author{
Gürkan Altuntaş ${ }^{1}$, Ali Aygün ${ }^{2}$, Murat Mümin Yazıc1 ${ }^{1}$, Melih İmamoğlu ${ }^{3}$, Selim Yurtsever ${ }^{1}$, Özlem \\ Bilir ${ }^{1}$ \\ ${ }^{1}$ Department of Emergency Medicine, Recep Tayyip Erdogan University Training and Education Hospital, Rize, Turkey \\ ${ }^{2}$ Department of Emergency Medicine, Ordu University, Faculty of Medicine, Ordu, Turkey \\ ${ }^{3}$ Department of Emergency Medicine, Rize State Hospital, Rize, Turkey
}

Received: 05 November 2018, Accepted: 26 November 2018, Published online: 27 December 2018

(C) Ordu University Institute of Health Sciences, Turkey, 2018

\begin{abstract}
Carbon monoxide is a gas formed by partial combustion of carbon containing fuels and leads to intoxication with various non-specific clinical findings. Although hookah is a common way of tobacco consumption among people living in the Middle East, Asia and Africa, it has become popular in European countries and United States of America (USA). In our country, hookah smoking is especially common among young people and more common in cafes. In our case report, two cases with carbon monoxide (CO) poisoning findings after smoking hookah. In both cases, non-specific clinical findings were observed after hookah smoking and blood carboxyhemoglobin fraction $(\mathrm{FCOHb})$ levels were higher than normal values in laboratory parameters. Key words: Carbon monoxide, hookah, intoxication
\end{abstract}

Address for correspondence/reprints:

Ali Aygün

Telephone number: +90 (505) 2681711

E-mail: dr_aliaygun@ hotmail.com

DOI: $10.19127 / \mathrm{mbsjohs} .478663$

\section{Introduction}

Carbon monoxide (CO) is a colorless, tasteless, odorless gas formed by partial combustion of carbon containing fuels and it has a 200 times greater binding affinity to hemoglobin than oxygen (Kesner et al., 2012). CO intoxication is one of the most common causes of morbidity and mortality in the world, which can be prevented and treated (Sircar et al., 2015). CO intoxication findings are seen in vital organs with high oxygen dependence such as central nervous system and cardiovascular system (Karaca et al., 2013). Suicidal or fire exposure related intoxications are more commonly reported in developed countries, whereas in our country, poisonings due to stoves, water heaters and combi boiler use are more common (Metin et al, 2011). The use of barbecues and hookah smoking in small areas with insufficient ventilation are rare causes of $\mathrm{CO}$ intoxication. Hookah is a common way of tobacco consumption among people living in the Middle East, Asia and Africa. Nowadays, it is becoming 
more popular in European countries and United States of America. In our country, hookah smoking is more common among young people (Kocak et al., 2017). In our case report, we aimed to discuss two cases of $\mathrm{CO}$ intoxication with different clinical findings after hookah smoking and to draw attention to the risks of hookah smoking.

\section{Case 1}

A 37-year-old male was brought to the emergency department with presyncope. His general status was good, oriented and cooperative. Glasgow Coma Score (GCS) was 15, blood pressure was $120 / 80 \mathrm{mmHg}$, heart rate was $80 / \mathrm{min}(\mathrm{min}$ ) and respiratory rate was $22 / \mathrm{min}$. In his detailed anamnesis, he described nausea, dizziness and faintness after smoking hookah in an outdoor café for about 1 hour. In his background story, there is no features other than smoking. He did not describe any illicit substance intake. Detailed physical examination revealed no abnormal findings. His 12lead ECG was normal. Blood hemogram and biochemical values were normal. Cranial imaging of the patient did not show any abnormal findings. In the arterial blood gas analysis of the patient, carboxyhemoglobin fraction (FCOHb) was measured as $32.3 \%(0.5-1.5 \%)$. The patient was diagnosed as $\mathrm{CO}$ intoxication and normobaric oxygen (O2) therapy (at a rate of $10 \mathrm{lt} / \mathrm{min}$ ) was started with a reservoir mask. After 12 hours of oxygen therapy, the FCOHb levels regressed to normal values and no impairment was observed in the patient's clinic. The patient was completely recovered and discharged from the emergency department.

\section{Case 2}

A 25-year-old male patient was admitted to the emergency department with headache, discomfort, numbness in the hands, nausea, chest pain and tachycardia. GCS was 15, blood pressure was 120/70 $\mathrm{mmHg}$, heart rate was 118 / min and respiratory rate was $25 / \mathrm{min}$. In the detailed anamnesis of the patient, he described hookah smoking in a café for about 40 minutes. The patient described that his complaints had begun after smoking hookah. His 12-lead ECG revealed sinus tachycardia. FCOHb was measured as $28.5 \%(0.5-1.5 \%)$ in the arterial blood gas. Other laboratory parameters were normal. The patient was diagnosed as $\mathrm{CO}$ intoxication and treated with normobaric $\mathrm{O} 2$ (at a rate of $10 \mathrm{lt} / \mathrm{min}$ ). After 8 hours, $\mathrm{FCOHb}$ levels regressed to normal values and the patient whose clinical findings were stable discharged with full recovery. After 8 hours, FCOHb levels regressed to normal values and the patient whose clinical findings were stable discharged with full recovery.

\section{Discussion}

Although hookah is a common way of tobacco consumption among people living in the Middle East, Asia and Africa, it has become popular in European countries and United States of America (USA). Especially among the young-adults, the use in cafes has become widespread (Kocak et al., 2017). Hookah consists of various shapes, sizes, materials and colors. A typical hookah contains the following sections (Figure 1) (Karaca et al., 2013);

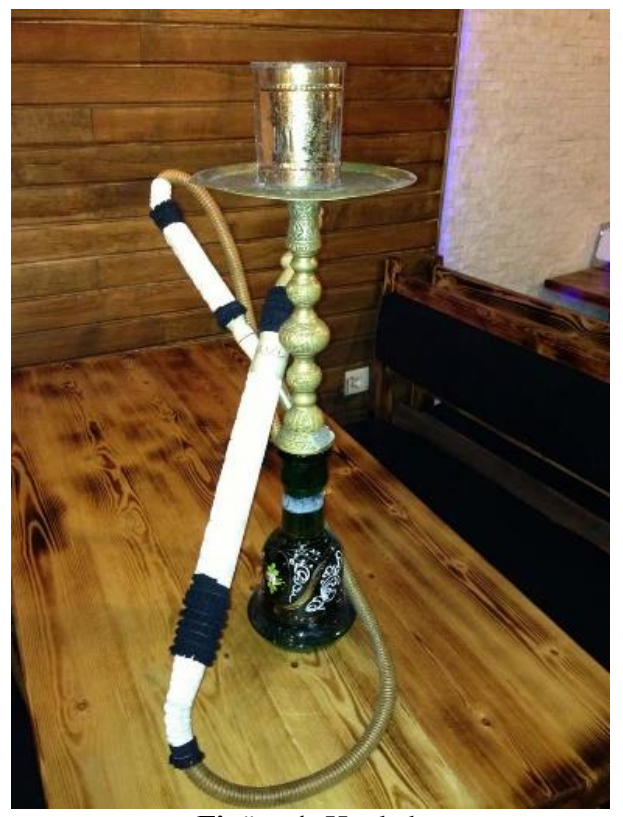

Figüre 1: Hookah

1. A pit head located at the top, where the tobacco is placed and usually burned with embers.

2. A jug or bottle of water to filter smoke.

3. The long body of the hookah that connects the head to the bowl and carries the smoke into the water through a tubular line.

4. Tube (hookah tube) that takes the smoke from the bottle and delivers it to the mouth

When a person inhales from hookah tube, the smoke draws from the reservoir and then passes through the water in the bottle and reaches the smoker. The water in the hookah, cools the smoke and filters some of the tar and some particles in the smoke (Ozkan et al., 2013). Water in the hookah, filters only a small part of the harmful substances. Longer duration of hookah smoking and deep 
inhalation with less irritant effect of water moistened smoke causes more $\mathrm{CO}$ is exposed than cigarette (Shihadeh and Saleh, 2005). Also, due to the coal used to burn the hookah tobacco, the $\mathrm{CO}$ concentration increases (Knishkowy and Amitai, 2005). In addition, hookah is often smoked in indoor areas and this leads to CO level increase in area due to accumulation of smoke, and the $\mathrm{O} 2$ level decreases in the opposite direction. This increases the likelihood of CO intoxication for people who smoke hookah.

The clinical signs and symptoms of $\mathrm{CO}$ intoxication may be non-specific. The best method for detecting intoxication is clinical suspect. Although nonspecific symptoms such as fatigue, nausea, vomiting, headache, and dizziness are observed, loss of consciousness, seizures, cardiac arrhythmias, myocardial ischemia and even death may develop. The severity of toxicity is related to the current chronic diseases, advanced age and $\mathrm{CO}$ exposure time (Von Rappard et al., 2014; Ozkan et al., 2013).

After evaluating vital functions, the basis of treatment of $\mathrm{CO}$ intoxication cases is $\mathrm{O} 2$ support. In order to eliminate $\mathrm{CO}$ from circulation, normobaric or hyperbaric oxygen therapy can be used. While the half-life of $\mathrm{CO}$ in room air is 4-5 hours, it may decrease to 60 minutes with normobaric oxygen therapy and to 20 minutes with hyperbaric oxygen therapy. Treatment continues until patients become asymptomatic and until the level of blood FCOHb is lower than 10\% (Kao and Nanagas, 2004; Yurtseven et al., 2015).

\section{Conclusion}

As seen in our cases, $\mathrm{CO}$ intoxication can be encountered in patients presenting with nonspecific symptoms after hookah smoking. Physicians should keep CO intoxication in mind in the differential diagnosis of patients presenting with nonspecific symptoms to the emergency room and focus on detailed anamnesis; and should not forget that $\mathrm{CO}$ intoxication due to hookah use can be seen.
Patient.Approval: Approval was received for this study from the patient.

Peer-review: Externally peer-reviewed.

Author Contributions: Concept - G.A, M.M.Y, S.Y., Design - G.A, M.M.Y, S.Y.; Supervision M.I., A.A.; Materials - G.A, M.M.Y, S.Y.; Data Collection and/or Processing - G.A, M.M.Y, S.Y.; Analysis and/or Interpretation - G.A, M.M.Y, S.Y., M.I.; Literature Review - G.A, M.M.Y; Writing G.A, M.M.Y, M.I., A.A.; Critical Review - A.A., O.B.

Conflict of Interest: No conflict of interest was declared by the authors.

Financial Disclosure: The author declared that this study hasn't received no financial support.

\section{References}

Kao LW, Nanagas KA. Carbon monoxide poisoning. Emerg Med Clin N Am.2004;22:985e1018.

Karaca Y, Eryigit U, Aksut N, Turkmen S. Syncope associated with water pipe smoking. BMJ Case Rep 2013. doi:10.1136/bcr-2013009526.

Kesner KL, Ramaiah VK, Hemmer LB, Koht A. Anesthesia implications of waterpipe use. Journal of clinical anesthesia 2012;24(2), 137-140.

Knishkowy B, Amitai Y. Water-pipe (Narghile) Smoking: an emerging health risk behavior. Pediatrics 2005;116(1):113-119.

Kocak AO, Akbas İ, Cakır Z. Carbon monoxide poisoning due to water pipe smoking: case series. Akademik Acil Tip Olgu Sunumlari Dergisi, 2017;8: 27-30.

Metin S, Yıldız S, Çakmak T, Demirbas S. Frequency of carbon monoxide poisoning in Turkey in 2010. TAF Preventive Medicine Bulletin, 2011;10(5), 587-592.

Ozkan S, Ozturk T, Ozmen Y, Durukan P. Syncope associated with carbon monoxide poisoning due to narghile smoking. Case reports in emergency medicine, 2013. http://dx.doi.org/10.1155/2013/796857 
Shihadeh A, Saleh R. Polycyclic aromatic hydrocarbons, carbon monoxide, "tar", and nicotine in the mainstream smoke aerosol of the narghile water pipe. Food and Chemical Toxicology, 2005;43(5), 655-661.

Sircar K, Clower J, Kyong SM, Bailey C, King M, Yip F. Carbon monoxide poisoning deaths in the United States, 1999 to 2012. The American journal of emergency medicine, 2015 Sep;33(9):1140-5.

Von Rappard J, Schönenberger M, Bärlocher L. Carbon monoxide poisoning following use of a water pipe/hookah. Dtsch Arztebl Int 2014;111(40): 674-9; $\quad$ DOI: 10.3238/arztebl.2014.0674

Yurtseven S, Arslan A, Eryigit U, Gunaydin M, Tatli O, Ozsahin F, et al. Analysis of patients presenting to the emergency department with carbon monoxide intoxication. Turk J Emerg Med. 2015;15(4):159-62. pmid:27239619. 